\title{
Neurosurgery rounds: questions and answers (2nd edition) (2017) by Mark R. Shaya, Cristian Gragnaniello, and Remi Nader 520 pp., 160 illustrations paperback/softback ISBN: 9781626233461 Thieme Publishers New York/Stuttgart
}

\author{
Alexander Lilja-Cyron ${ }^{1}$
}

Received: 31 July 2018 / Accepted: 5 August 2018 / Published online: 8 August 2018

(C) Springer-Verlag GmbH Austria, part of Springer Nature 2018

This paperback pocket book consists of 520 pages with $1600+$ brief questions and answers in all areas of the neurosurgical specialty as well as adjacent disciplines such as neuropathology, neurophysiology, and neuroradiology. The book is aimed at medical students and junior residents for quick study sessions doing busy hospital shifts. With its question-based structure, it is not intended as a comprehensive handbook (like Mark S. Greenberg's "Handbook of Neurosurgery"), but rather as a tool for self-assessment and a way to focus reading in the first preparations for a career in neurosurgery including board exams.

The book is divided into nine chapters, i.e., neuroanatomy, neurophysiology, neuropathology, and neuropharmacology (the basic neuroscience chapters), followed by clinical chapters, i.e., cranial neurosurgery, spine, peripheral nerves, neurology, and neuroradiology. Each chapter is further divided into subsections, such as congenital, trauma, epilepsy, neoplastic, and degenerative in the chapter on neuropathology, and ends with a reference list for further reading. The last section of the book is an index that allows identification of questions (or answers) relating to specific subjects.

Questions are formulated as a short sentence and are directly followed by the answer as a short paragraph. Both questions and answers often include additional information provided in schematic drawings (e.g., the structure of the GABA receptor), pictures (e.g., histology

Alexander Lilja-Cyron

alexander.lilja-cyron@ regionh.dk

1 Department of Neurosurgery, Rigshospitalet, Blegdamsvej 9, 2100 Copenhagen, Denmark stains), tables (e.g., classification of astrocytic tumors), or radiographs (e.g., MRI/CT scans or angiograms). In two thirds of the chapters (both some basic and some clinical neuroscience chapters), the final subsection consists of more elaborate questions and answers formulated as "cases." Both questions and answers are generally well written with short and concise sentences and most questions are relevant for trainees in neurosurgery. Being the second edition of the book, there are very few misspellings or flaws in general.

The three authors are neurosurgeons and additionally the book has received contributions from subspecialists in pediatric, spinal, and cranial neurosurgery, and it has been reviewed by specialists in areas linked closely to neurosurgery, e.g., neuropathology and neuroradiology. The authors are American and compared to Europe or other parts of the world, there might be minor differences in medical/surgical handling of specific conditions. However, since the vast majority of the questions relates to more general knowledge of (e.g.) the anatomy and physiology of diseases, the book is of value to trainees around the world.

The overall impression is a well-structured book which can be carried in a lab coat pocket during clinical internships, can be used for testing among fellow students, or serve as companion for studies at home. Text and figures are well chosen and most importantly, they are relevant and concise, inviting the reader to open the book in even short breaks between clinical duties on the ward. The book is recommended to neurosurgical trainees in the beginning of their career as a self-assessment tool to be used together with handbooks and more comprehensive neurosurgical textbooks. 